Article

\title{
Accelerated Weathering and Soil Burial Effect on Biodegradability, Colour and Textureof Coir/Pineapple Leaf Fibres/PLA Biocomposites
}

\author{
Ramengmawii Siakeng ${ }^{1}(\mathbb{D})$, Mohammad Jawaid ${ }^{2, *(D)}$, Mohammad Asim ${ }^{2}$ and \\ Suchart Siengchin $1, *$ (D) \\ 1 Department of Mechanical and Process Engineering, The Sirindhorn International Thai-German, \\ Graduate School of Engineering (TGGS), King Mongkut's University of Technology North Bangkok, \\ Bangkok 10800, Thailand; ramengmawii8@gmail.com \\ 2 Institute of Tropical Forestry and Forest Products (INTROP), Universiti Putra Malaysia, \\ Seri Kembangan 43400, Malaysia; khanfatehvi@gmail.com \\ * Correspondence: jawaid_md@yahoo.co.in (M.J.); suchart.s.pe@tggs-bangkok.org (S.S.)
}

Received: 21 November 2019; Accepted: 16 December 2019; Published: 16 February 2020

check for updates

\begin{abstract}
Accelerated weathering and soil burial tests on biocomposites of various ratios of coir (CF)/pineapple leaf fibres (PALF) with polylactic acid (PLA) were conducted to study the biodegradability, colour, and texture properties as compared with PLA.The biodegradability of a lignocellulosic composite largely depends on its polymer matrix, and the rate of biodegradation depends on many environmental factors such as moisture, light(radiation), temperature and microbes. Biodegradation was evaluated by soil burial and accelerated weathering tests. Changes in physical and morphological properties were observed in the biocomposites after weathering. These results allowed us to conclude that untreated CF/PALF/PLA biocomposites would be a more favourable choice owing to their better biodegradability and are suitable for the suggested biodegradable food packaging applications.
\end{abstract}

Keywords: biodegradability; accelerate weathering; soil burial; polylactic acid; coir fibres; pineapple leaf fibres

\section{Introduction}

Environmental concerns and awareness have paved the way to the development of biodegradable composites as a replacement for petroleum-derived or non degradable polymers. So, there is an increase in demand for natural fibre-based composites for commercial use in various industrial sectors [1]. A variety of biopolymers such as polylactic acid (PLA), polyhydroxyalkanoates (PHAs), and polybutylene succinate (PBS) are reported to be used as matrixes in composites. These biopolymers are naturally sourced and can potentially be combined with various natural fibres/lignocellulosic materials to produce biodegradable composites [2]. Natural fibres are sustainable materials in nature with advantages like lowcost, lightweight, renewability, and, most importantly, biodegradability [3,4].

The agricultural sector generates enormous amounts of agro-waste every year [5]. The lignocellulosic residues alone exceed 350 million tons per year and are poorly managed [6]. Recycling natural fibres by incorporating them into composites to manufacture renewable and biodegradable materials might help in waste reduction. This approach paves the way to the development of low-cost and biodegradable materials with promising characteristics [1]. This has also led to a considerable change in the research direction of fibre-reinforced polymer composites [7,8]. Natural-fibre-based biocomposites have been developed not only as a motivating factor for material scientists, but also as an opportunity to improve the lives of people globally by developing renewable and sustainable products. At present, plastic 
build up is a concerning matter due to its long-term environmental burden. A number of studies have shown that the seas and oceans are filled with plastic debris $[9,10]$ that affects more than 250 aquatic species [11]. Plastic degradation can be achieved by multiple processes such as heat/thermic reaction, light/photo-oxidative reaction, ultraviolet (UV) degradation, etc. [12]. Polymeric substances usually degrade under UV radiation [13]. UV radiation induces degradation/modification of the surface chemistry in the composites, commonly known as photo-degradation or photo-catalysis [14]. The time required for their complete disintegration varies from one to another depending on the properties of the polymer, the type of light exposure, or the oxidation period. The degradation period could be a couple of months or in the range of hundreds to thousands of years [15-17].

PLA is one of the most studied biopolymers as it has many unique characteristics, including good transparency, glossy appearance, high rigidity, and good processability. PLA is frequently used for packaging materials. However, there are some limitations, notably, its inherent brittleness and poor toughness, slow degradation rate, and high cost, which hinder its extensive application $[18,19]$. Even though there are many limitations due to its material properties, a number of these challenges are expected to be overcome through blending PLA with other polymers, reinforcing it with fibres or fillers and additives, etc. [2]. A proper blend of coir fibres (CF)/pineapple leaf fibres (PALF) in a PLA matrix can possibly be used to develop a hybrid biocomposite which can match the thermo-mechanical properties of synthetic polymers and fibre-based composites which are being used in the manufacturing of food packaging materials [20]. With advancements in biocomposite technology, reinforcement of biopolymers/polymers with natural fibres (CF/PALF) is a method that can balance the harm caused by synthetic plastics and polymers. This will ensure environmentally friendly food packaging materials with high barrier properties and biodegradability [21]. It is intended that the use of CF/PALF/PLA hybrid composites will contribute to sustainability and environmental load reduction by the substitution of conventional food packaging materials.

Natural fibre/polymer composites are subjected to photo radiation when exposed to direct sunlight; this disrupts the chemical bonding of polymers, causing colour fading and disintegration with greater reductions in wetter conditions, especially in humid areas with high microbial activity [22-24]. After weathering/ageing periods, the strength of composites declines due to degradation of the fibres and polymers. Ageing in lignocellulosic fibres occurs due to the absorption of UV-rays by lignin present in the fibre, the formation of quinoid structures, Norrish reactions, and photo yellowing which occurs in lignin [25-27].

The biodegradability of composite materials can be analysed through different methods such as natural and accelerated weathering tests or soil burial tests [28] in normal garden soils or composts, hydrothermal degradation, chemical degradation and microbial attack, etc. Natural ageing or decaying processes are influenced by natural elements or environmental conditions. The long-term performance of composites in an exposed environment is evaluated by real-time observations for a period of a number of years [29]. A two-year ageing study on jute/phenolic biocomposites was conducted underexposure to natural weathering. Observed polymer cracking, black spots, bulging, fibrillation, and decline in tensile strength (over 50\%) were reported [30]. Ochi [31] investigated the biodegradability of kenaf-reinforced PLA composites by composting for four weeks using a garbage-processing machine and reported a 38\% decreased in the composite weights. Chee et al. [32] studied the effects of soil burial and accelerated weathering on the thermal and biodegradability properties of bamboo/kenaf-reinforced epoxy hybrid composites. They reported that soil burial showed more prominent degradation as compared to accelerated weathering.

Accelerated weathering tests are conducted in weathering chambers that mimic natural environmental conditions and the harsh effects of prolonged outdoor exposure. The method is carried out by exposing composite samples to UV radiation and controlled moisture/humidity and temperature. Accelerated weathering testing is a much faster and more convenient alternative method to natural weathering processes, and in addition, it is reproducible method. Accelerated weathering tests were performed on a kenaf/HDPE composite by Umar et al. [33] to test its durability. They observed 
micro-cracking of the surface and reduced tensile property and concluded that the biodegradability of composites was better enhanced by natural fibre reinforcements. Similar work was done with coir fibre [34], ramie, flax, cotton [35], hemp [14], kenaf, rice husk [23], and others, where the biodegradability was enhanced by increasing fibre loading in the composites. PLA is easy to process, biocompatible, and biodegradable in natural environments such as normal soil, compost, and aqueous medium [36-38]. The most important quality of PLA/NF composites is acceptable biocompatibility and biodegradability [39]. Yusoff et al. [40] studied three types of hybrid biocomposites based on PLA biopolymer, namely, kenaf/coir/PLA, bamboo/coir/PLA, and kenaf/bamboo/coir/PLA hybrid biocomposites. They concluded that these hybrid composites are suitable for indoor structural applications while maintaining their biodegradability at the time of disposal.

To date, limited research has been done on biodegradability and the impact of environmental conditions on hybrid biocomposites. In the present study, a novel hybrid biocomposite comprising CF and PALF with PLA biopolymer was developed and proposed for food packaging applications, particularly food trays. CF/PALF/PLA hybrid composites provide an option of achieving a blend of properties such as stiffness, degradability, processability, and strength, which are the core necessities of food packaging materials. The impacts of various environmental conditions on the degradation and physical properties of the hybrid composites were analysed through accelerated weathering and soil burial tests. The hybrid biocomposites were fabricated by a melt-blending and compression moulding method, with 30\% fixed fibre loading by weight for different weight ratios of CF to PALF.

\section{Materials and Methods}

\subsection{Materials}

The PLA biopolymer used in this research was a general-purpose virgin pallet purchased from TT Biotechnologies Sdn. Bhd., Penang, Malaysia. The characteristics of PLA are shown in Table 1. The CF used in this research were supplied by Innovative Pultrusion Sdn Bhd.,Seremban, Malaysia, while PALF were procured from the southern part of India. The basic information regarding these fibres' properties isdisplayed in Table 2. Sodium Hydroxide $(\mathrm{NaOH})$ flakes used for fibre treatment were supplied by Evergreen Engineering \& Resources, Selangor, Malaysia.

Table 1. Properties of polylactic acid (PLA) biopolymer [19].

\begin{tabular}{cccc}
\hline Characteristics & Description & Characteristics & Description \\
\hline Physical state & Pallets & Tensile strength & $14.68 \mathrm{MPa}$ \\
Colour & Translucent white & Young's Modulus & $3.98 \mathrm{GPa}$ \\
Odour & No odour & Flexural strength & $27.87 \mathrm{MPa}$ \\
Density & $1.25 \mathrm{~g} / \mathrm{mol}$ & Flexural modulus & $3.75 \mathrm{GPa}$ \\
Melting point & $150-170{ }^{\circ} \mathrm{C}$ & Impact strength & $3.43 \mathrm{~kJ} / \mathrm{m}^{2}$ \\
Glass transition temperature & $55-60{ }^{\circ} \mathrm{C}$ & Water absorption & $2.58 \%$ \\
Molecular weight & $74,000 \mathrm{~g} / \mathrm{mol}$ & Thickness swelling & $1.42 \%$ \\
\hline
\end{tabular}

Table 2. Properties of coir fibres (CF) and pineapple leaf fibres (PALF) [20].

\begin{tabular}{ccc}
\hline Properties & CF & PALF \\
\hline Density $\left(\mathrm{g} / \mathrm{m}^{3}\right)$ & 1.20 & 1.07 \\
Diameter $(\mu \mathrm{m})$ & $100-450$ & $20-80$ \\
Cellulose $(\%)$ & 42.14 & 81.27 \\
Hemicelluloses $(\%)$ & 15.17 & 12.31 \\
Lignin $(\%)$ & 35.25 & 3.46 \\
Moisture absorption $(\%)$ & 10.00 & 11.80 \\
Microfibrillar angle $\left({ }^{\circ}\right)$ & $30-45$ & $8-15$ \\
Elongation at break $(\%)$ & $17-47$ & $1.6-4$ \\
Tensile Strength $(\mathrm{MPa})$ & $105-175$ & $413-1627$ \\
Youngs Modulus $(\mathrm{GPa})$ & $4-6$ & $34.5-82.5$ \\
\hline
\end{tabular}




\subsection{Fibre Treatment}

$\mathrm{CF}$ and PALF were immersed in alkaline solution $(6 \% \mathrm{NaOH})$ for $3 \mathrm{~h}$. After immersion, these fibres were washed with tap water to attain neutral $\mathrm{pH}$. Washed fibres were air dried under room temperature for $48 \mathrm{~h}$. The methods relating to chemical selection, chemical concentration, and soaking time for this surface treatment were adopted from our previous published paper [41].

\subsection{Composites Fabrication}

CF and PALF were chopped into short fibres using a ring flaker machine; different fibre lengths were separated by mechanical sieves, and 1-2 mm length fibres were utilised for fabricating the composites. PLA pellets and fibres were dried at $80{ }^{\circ} \mathrm{C}$ for $24 \mathrm{~h}$ in a hot air oven.CF/PALF/PLA biocomposites were prepared by melt blending in an internal mixer at $180{ }^{\circ} \mathrm{C}$ temperature and $50 \mathrm{rpm}$ speed for $10 \mathrm{~min}$. The fibre loading was fixed at $30 \mathrm{wt} \%$ with different CF-to-PALF ratios (3:7, 1:1, and 7:3). The different weight percentages of CF and PALF in the PLA hybrid composites are shown in Table 3. Two different batches of each combination were prepared to verify reproducibility. The hybrid composites were compression moulded in a heated press at $180^{\circ} \mathrm{C}$ for $10 \mathrm{~min}$. After compression moulding, the samples were quenched using a water-cooled press and stored at room temperature before subsequent characterisation. Developed hybrid composites were cut into different shapes and sizes according to the respective characterisations and standards.

Table 3. Formulation of CF/PALF/PLA biocomposites.

\begin{tabular}{cccc}
\hline Designation & $\begin{array}{c}\text { PLA } \\
\text { (Weight \%) }\end{array}$ & $\begin{array}{c}\text { CF } \\
\text { (Weight \%) }\end{array}$ & $\begin{array}{c}\text { PALF } \\
\text { (Weight \%) }\end{array}$ \\
\hline Pure PLA & 100 & - & - \\
C-30 & 70 & 30 & - \\
C7P3 & 70 & 21 & 9 \\
C1P1 & 70 & 15 & 15 \\
C3P7 & 70 & 9 & 21 \\
P-30 & 70 & - & 30 \\
\hline
\end{tabular}

\subsection{Accelerated Weathering Test}

Accelerated weatheringwas carried out in an accelerated weathering chamber (Model QUV/Spray) in accordance with ASTM G 154-16 (2016). A UVA fluorescent bulb with $0.68 \mathrm{~W} / \mathrm{m}^{2}$ irradiance at $340 \mathrm{~nm}$ wavelength was used with cycles of $1 \mathrm{~h} \mathrm{UV}$ irradiation, followed by $1 \mathrm{~min}$ spray with de-ionised water and a subsequent $2 \mathrm{~h}$ condensation while maintaining a temperature/RH of $50{ }^{\circ} \mathrm{C} / 55 \%$ and above. Samples of sizes $5^{\prime \prime} \times 3^{\prime \prime} \times 0.13^{\prime \prime}$ were subjected to the weathering process for a duration of $250 \mathrm{~h}$ in the ageing chamber. The changes in the surface colour, surface texture, and weight of the tested samples were evaluated after $250 \mathrm{~h}$ of weathering and then compared with the unweathered samples.

\subsubsection{Weight Change}

The weight change of the accelerated weathered samples was calculated and evaluated by the following equation:

$$
\text { WeightLoss }(\%)=[\text { W0 }- \text { W1/W0 }] x 100
$$

where $W 0$ and $W 1$ are the weights of the sample before and after accelerated weathering, respectively.

\subsubsection{Colorimetric Colour Analysis}

The surface colour of the biocomposites were measured using chroma-meter (Konica Minolta Colorimeter, Bangi, Malaysia) according to the CIE $L^{*} a^{*} b^{*}$ colour system by Lab Colour Space. The lightness $\left(L^{*}\right)$ and two chromaticity coordinates $\left(a^{*}\right.$ and $\left.b^{*}\right)$ were measured for independent specimens at four different positions on each. 


\subsubsection{Surface Texture Measurement}

Surface texture measurement was carried out in order to investigate the change in roughness of the samples'surfaces to evaluateof the degree of degradation by accelerated weathering. The surface texture (roughness) was measured usinga surface roughness tester (Surftest SV-3100 Bangi, Malaysia) in measuring conditions of measuredlength $(X), 17.5000 \mathrm{~mm}$; measured pitch, $0.0010 \mathrm{~mm}$; Z1-axis range, $0.0800 \mathrm{~mm}$; stylus radius compensation, $0.000000 \mathrm{~mm}$; and $\mathrm{Z}$ gain adjusted ratio of 1.005017 by the $\mathrm{X}$-axis pitch sampling method with nonpolar reversal and a measuring speed of $1.00 \mathrm{~mm} / \mathrm{s}$.

\subsection{Soil Burial Test}

Biodegradation tests on the CF/PALF/PLA biocomposites and neat PLA samples were carried outby a simple soil burial test, ASTM D570-98 (1998), to simulate the natural biodegradation of biocomposites. Dog-bone-shaped samples were prepared according to ASTM 638-14 (2014) and were buried in natural soil in a plastic bag without any enzyme activity or any composting materials. They were located outdoors with an average temperature and relative humidity of $30^{\circ} \mathrm{C}$ and $80 \%$, respectively. The buried samples were removed at regular intervals $(30,60,90,120$, and 150 days) for different characterisations. After each interval of soil burial, the samples were washed thoroughly with water to remove the soil debris from the surface of the samples. Samples were airdried at room temperature until theyreached a constant weight. The biodegradability was evaluated by measuring and comparing the weight change (loss) before and after burial. The weight losses of buried samples were calculated using the following Equation (1). In addition, the surface appearances of the buried samples were evaluated by using Image Analyser for visual comparison.

\section{Results}

\subsection{Accelerated Weathering: Weight Change}

Figure 1 illustrates weight change against exposure time for the biocomposites and PLA samples. It is clear that all samples gained weight up to some extent which was then lost after drying due to the biodegradation of the biocomposites. The weight gain was due to the hydrophilic properties of CF and PALF [42]. The weight loss was less than $0.5 \%$ for neat PLA. The calculated weight loss was less than $2 \%$ for untreated C30 and less than 1\% for untreated P30 biocomposite samples, while it was about $1.25 \%$ for all the untreated hybrid CF/PALF/PLA samples. Furthermore, the weight loss was less than $1 \%$ for all alkali-treated biocomposites and hybrid biocomposites. Thus, it was established that mercerisation of both CF and PALF makes them more stable in comparison with untreated CF- and PALF-based biocomposites. This may be due to enhanced interfacial adhesion between the fibres and matrix and/or improved interfacial bonds caused by improved hydrophobicity in biocomposites fabricated with alkali-treated fibres [43]. The calculated weight loss values were highest for the untreated C7P3 among the hybrid biocomposites, containing 70\% untreated CF and 30\% untreated PALF, owing to the high content of $\mathrm{CF}$ which is a lignin-rich natural fibre. 


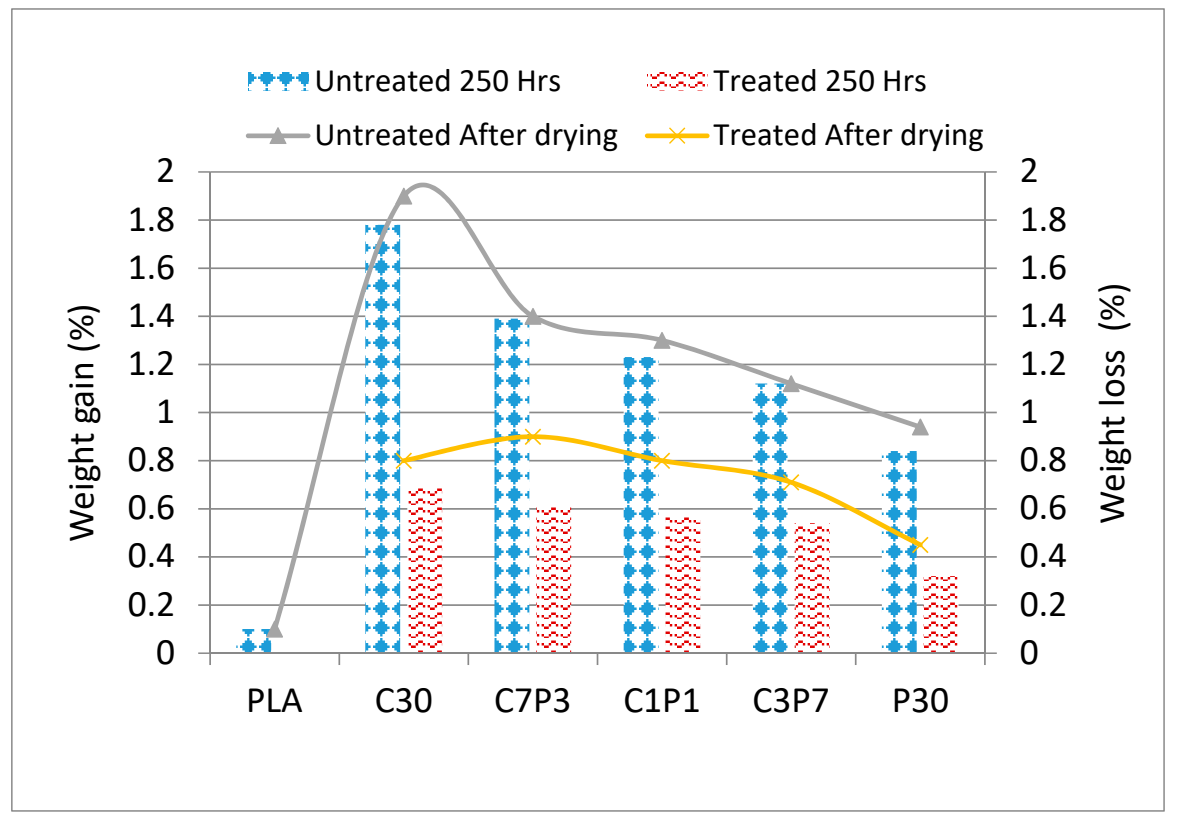

Figure 1. Change in weight over time for CF/PALF/PLA biocomposites, hybrid biocomposites, and PLA.

It can be seen from Figure 2 that the neat PLA sample remained nearly the same, without any visible discolouration or change in its original shape, whereas the biocomposites crumbled, forming fractures, cracks, and holes on the surface. The percentage weight loss in all the biocomposites were in a linear relationship with the progression of degradation. Similar observations were reported by Umar et al. [44] of the effect of accelerated weathering on kenaf/HDPE composites. According to Mehta et al. [42], these fractures, cracks, and holes were produced by the degradation of fibres. Nonetheless, differences in the degree of degradation were observed among the biocomposites with and without alkali-treated fibres. That is, the loss of shape or warping occurred slower in the biocomposites with alkali-treated fibres as compared to untreated CF/PALF/PLA biocomposites. We assume that this happened due to improved interfacial bonding between CF/PALF and PLA in the alkali-treated biocomposites, owing to the reduced hydrophilicity of alkali-treated fibres.
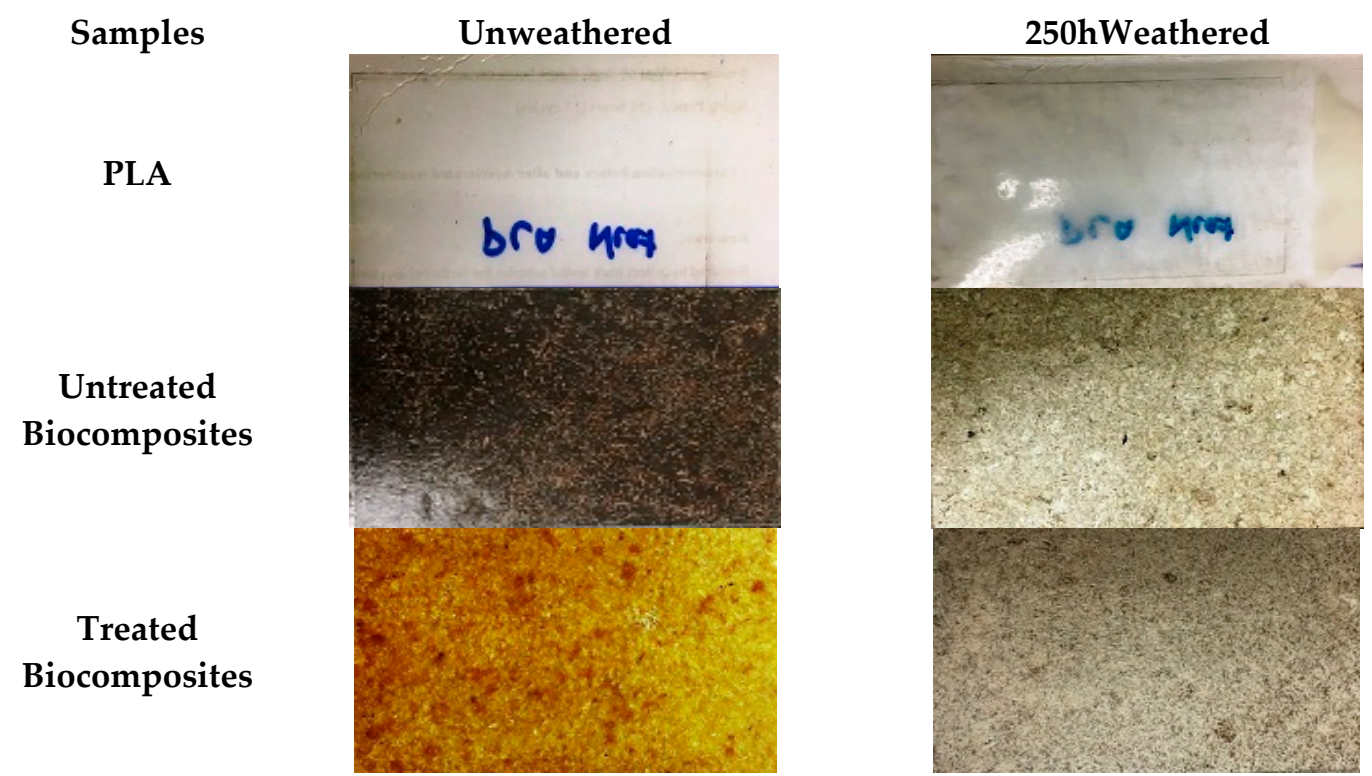

Figure 2. Images of unweathered and accelerated weathered untreated and treated CF/PALF/PLA biocomposites and PLA 


\subsection{Accelerated Weathering: Surface Roughness}

Surface texture measurements were carried out in order to investigate the change in roughness of the tested surfaces to evaluate the degree of degradation by accelerated weathering.

Figure 3 shows the change in surface roughness parameter Ra before and after accelerated weathering for untreated and alkali-treated CF/PALF/PLA biocomposites as well as neat PLA against exposure time, i.e., $250 \mathrm{~h}$. Generally, the textures of the biocomposite samples became rougher with increasing weathering time [42]. Ra had the lowest values among all the surface roughness parameters, followed by Rz and Rmax with the highest values, as displayed in Table 4 . The roughness parameters of the sample C30 A were the highest, followed by P30 A, followed by the C3P7A and C1P1A hybrid biocomposites. The untreated C7P3 hybrid biocomposite sample showed the lowest values of surface roughness parameters. In general, alkali-treated fibre biocomposites had higher surface roughness compared to untreated biocomposites. The C3P7A hybrid biocomposite sample showed the highest surface texture change among the hybrid biocomposites.

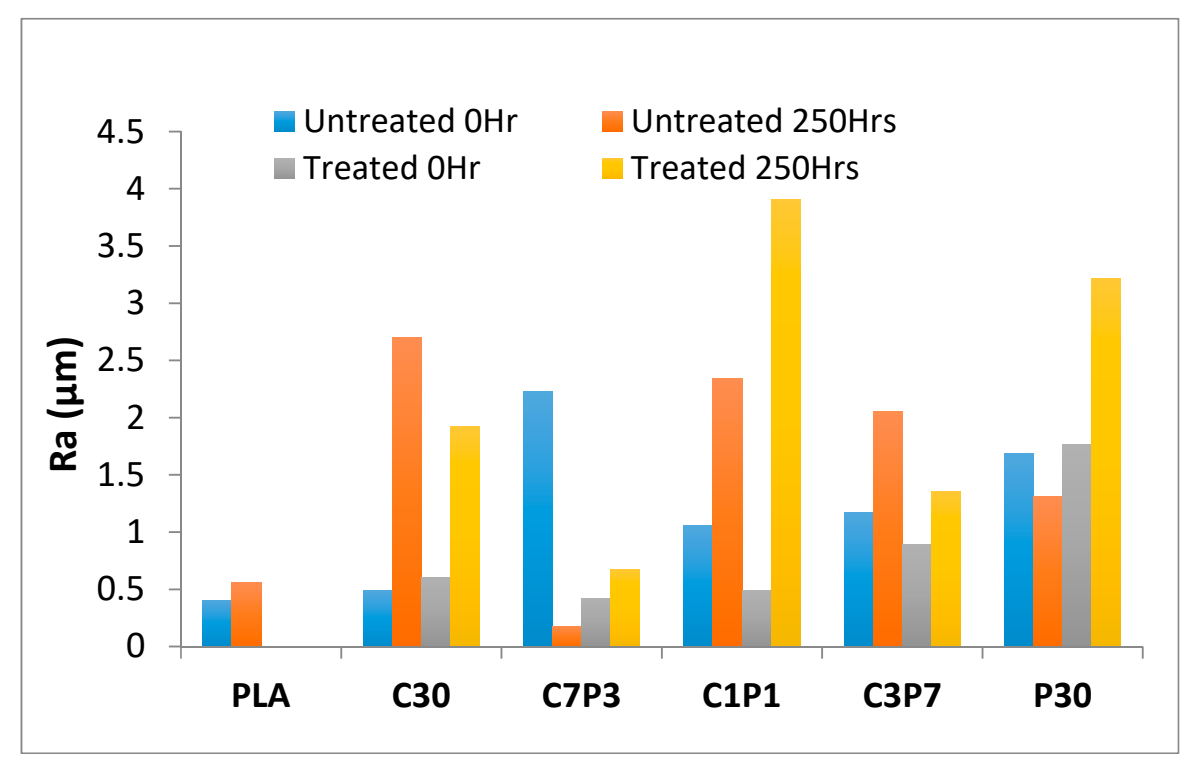

Figure 3. Change in surface roughness parameter Ra over time for PLA and untreated and alkali-treated CF/PALF/PLA biocomposites.

In the accelerated weathering chamber, the test samples were sprinkled with water to adjust the environment relative humidity, irradiated by UV-rays, and reacted with ambient oxygen $[25,26]$. These environmental conditions lead to breakage of the bonds between the fibres and the polymer matrix, which caused the biocomposite surfaces to crumble [42]. This spread through the thickness of the biocomposites over the exposure time via various reactions and processes such as oxidation, reduction, hydrolysis, dehydration, matrix crystallisation, swelling, shrinking, freezing, cracking, and interfacial degradation [43,45]. The major constituents responsible for the absorption of moisture in the fibres are (i) hemicellulose, (ii) accessible cellulose, (iii) non-crystalline cellulose, (iv) lignin, and (v) crystalline cellulose, in descending order. The major constituents responsible for UV degradation are (i) lignin, (ii) hemicellulose, (iii) accessible cellulose, (iv) non-crystalline cellulose, and (v) crystalline cellulose, whilst hemicellulose, cellulose, and lignin are the constituents responsible for thermal degradation [45]. The biological degradation of fibre is influenced greatly by hemicelluloses, followed by accessible cellulose and non-crystalline cellulose [42,46]. 
Table 4. Surface texture measurements: roughness parameter summary sheet of untreated and alkali-treated CF/PALF/PLA biocomposites.

\begin{tabular}{ccccccc}
\hline \multirow{2}{*}{ Sample } & \multicolumn{3}{c}{ Before } & \multicolumn{3}{c}{ After } \\
\cline { 2 - 7 } & $\mathbf{R a}(\mu \mathbf{m})$ & $\mathbf{R m a x}(\mu \mathbf{m})$ & $\mathbf{R z}(\mu \mathbf{m})$ & $\mathbf{R a}(\mu \mathbf{m})$ & $\mathbf{R m a x}(\mu \mathbf{m})$ & $\mathbf{R z}(\mu \mathbf{m})$ \\
\hline PLA & 0.4041 & 4.1468 & 2.9805 & 0.5611 & 5.8276 & 3.9426 \\
C30 & 0.4878 & 18.0561 & 4.2805 & 2.7034 & 57.5719 & 23.4164 \\
P30 & 1.6913 & 39.2247 & 19.9636 & 1.3076 & 20.4452 & 9.4624 \\
C3P7 & 1.1726 & 30.6461 & 22.0001 & 2.0524 & 47.5884 & 18.2854 \\
C1P1 & 1.0534 & 22.6111 & 14.3713 & 2.3452 & 34.8313 & 21.6659 \\
C7P3 & 2.2285 & 23.7508 & 16.5913 & 0.1773 & 10.6666 & 3.0401 \\
C30 A & 0.6067 & 16.4739 & 6.0132 & 1.9237 & 66.6887 & 22.2321 \\
P30 A & 1.7618 & 13.5416 & 11.4903 & 3.2163 & 64.6825 & 35.9024 \\
C3P7 A & 0.8875 & 7.2143 & 3.3644 & 1.3577 & 62.3672 & 20.7893 \\
C1P1 A & 0.4864 & 16.4976 & 3.7916 & 3.9073 & 62.2191 & 36.5664 \\
C7P3 A & 0.4231 & 11.0194 & 4.7770 & 0.6759 & 28.9814 & 9.6606 \\
\hline
\end{tabular}

\subsection{Accelerated Weathering: Colour Change}

The Lab colour space is a colour-opponent space with dimension " $L$ " for lightness and " $a$ " and " $b$ " for the colour opponent dimensions. Inthe Lab scale, " $L$ " is light to dark, " $a$ " is green to red, and " $b$ " is blue to yellow [47].

Figure 4 illustrates the cumulative colour changes $(\mathrm{dE})$ in the biocomposite samples with exposure time. According to the CIEL ${ }^{*} a^{*} b^{*}$ colour system, there are three parameters for colour: lightness $\left(L^{*}\right)$ and two chromaticity coordinates $\left(a^{*}\right.$ and $\left.b^{*}\right)$. Here, $+a^{*}$ to $-a^{*}$ denotes red and green, $+b^{*}$ to $-b^{*}$ is for yellow and blue, and $L^{*}$ varies from black (0) to white (100). The value changes in $L^{*}, a^{*}$, and $b^{*}$ were used to determine the cumulative colour change of the samples, $\mathrm{dE}^{*}$ [48]. On average, the $\mathrm{d} L$ values of all the untreated biocomposites increased from 25 at $0 \mathrm{~h}$ exposure to 70 for $250 \mathrm{~h}$ exposure. This was due to the change in biocomposite colour from medium and dark brown to greyish white after UV irradiation and exposure to moisture, condensation, and relative humidity. On the other hand, the neat PLA sample showed decreased $d L$ values from 82.34 to 58.65 after the weathering test. This was because the sample changed from transparent to a milky white colour due to a reduction in the transparency of the polymer [49]. After alkali treatment of the fibres, the $\mathrm{d} L$ values of composites increased from 25 to 65 on average, except for the P30 A sample, which showed an increase in $\mathrm{d} L$ from 51 to 71 as the colour of the PALF was already very pale prior to alkali treatment. The multiple action of moisture, oxygen, and UV-ray exposure induced the colour change of these biocomposite samples [42]. The change in $L$ was less distinct for alkali-treated hybrid biocomposites such as C3P7A, C1P1A, and C7P3A which have both the lightness from PALF and darkness from CF in proportion. This indicates that fibres with alkali treatment retained a higher amount of hydrophobicity due to surface protection against photo-oxidation [43]. 
Increases in the values of da from 0 for all weathered samples were observed, whereas reductions in the values of $\mathrm{dB}$ from 0 to $250 \mathrm{~h}$ were recorded in all untreated biocomposites, hybrids, and neat PLA samples, but increased values were observed in alkali-treated C30 and C3P7 hybrid biocomposites. As shown in Table 5, the overall colour change parameter (dE) increased from $\sim 40$ to $\sim 80$ for all biocomposites except for the alkali-treated P30 and neat PLA samples, both of which had lighter colours prior to accelerated weathering. The $\mathrm{dE}$ values of untreated hybrid biocomposites such as C3P7, C1P1, and C7P3 were higher than those of alkali-treated hybrid biocomposites. A slightly higher colour change occurred in untreated P30 biocomposites compared to untreated C30 biocomposites.

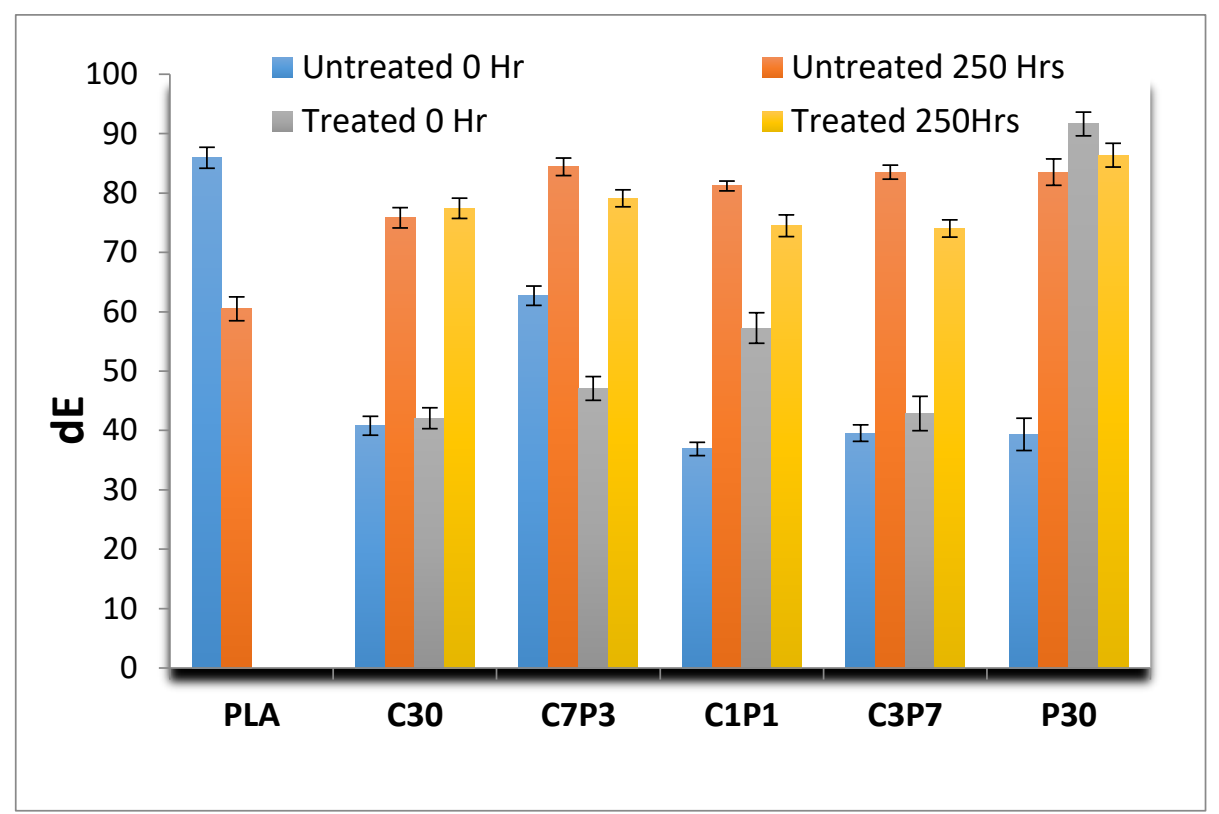

Figure 4. Cumulativecolour change (dE) over time for untreated and alkali-treated CF/PALF/PLA biocomposites.

Table 5. Colour change parameter summary sheet of PLA and untreated and alkali-treated CF/PALF/PLA composites using the CIELab system.

\begin{tabular}{ccccccccc}
\hline \multirow{2}{*}{ Sample } & \multicolumn{3}{c}{ Before Weathering } & \multicolumn{3}{c}{ After 250 h Weathering } \\
\cline { 2 - 9 } & $\boldsymbol{L}^{*}$ & $\boldsymbol{a}^{*}$ & $\boldsymbol{b}^{*}$ & $\mathrm{dE}$ & $\boldsymbol{L}^{*}$ & $\boldsymbol{a}^{*}$ & $\boldsymbol{b}^{*}$ & $\mathrm{dE}$ \\
\hline PLA & 82.34 & 0.52 & 3.07 & 85.93 & 58.65 & 1.29 & 0.55 & 60.49 \\
C30 & 24.92 & 7.52 & 8.36 & 40.80 & 64.13 & 3.84 & 7.85 & 75.82 \\
P30 & 23.27 & 7.75 & 8.33 & 39.35 & 75.48 & 1.27 & 6.76 & 83.51 \\
C3P7 & 25.50 & 6.65 & 7.41 & 39.56 & 75.46 & 1.89 & 6.37 & 83.51 \\
C1P1 & 23.56 & 6.44 & 6.89 & 36.89 & 73.64 & 2.03 & 5.51 & 81.18 \\
C7P3 & 37.66 & 9.23 & 15.81 & 62.70 & 65.24 & 5.78 & 13.39 & 84.41 \\
C30 A & 25.02 & 7.65 & 9.40 & 42.07 & 63.23 & 4.40 & 9.79 & 77.42 \\
P30 A & 51.75 & 9.93 & 29.94 & 91.62 & 71.33 & 3.84 & 11.20 & 86.37 \\
C3P7 A & 28.29 & 6.51 & 8.06 & 42.86 & 60.15 & 3.69 & 10.18 & 74.02 \\
C1P1 A & 31.42 & 8.71 & 17.13 & 57.26 & 63.04 & 3.18 & 8.26 & 74.48 \\
C7P3 A & 28.78 & 7.54 & 10.76 & 47.08 & 66.54 & 3.58 & 8.98 & 79.10 \\
\hline
\end{tabular}

\subsection{Soil Burial: Weight Loss}

It has been confirmed that PLA degrades naturally in soil, though it is less prone to degradation compared to other aliphatic biodegradable polymers exposed in a natural environment [50]. PLA degradation in soil is reported to occur by two processes:hydrolysis and conversion of lactic acid into gas and water. In the early stage of degradation, molecular chains of PLA are hydrolysed from higher to lower molecular weight, which can be accelerated by acids or bases. Moisture and 
temperature also affect this hydrolysis [51]. In this step, some bacteria and fungi in the soil catalyse the degradation via hydrolytic scission of ester groups into acid and alcohol, ultimately converting the lactic acid molecules into $\mathrm{CO}_{2}$, water, and biomass [52]. It is possible that the degradation generally proceeds from the interior of the samples and that the diffusion rate of degradation products is rather slow [34]. In contrast, soil microbes can easily degrade CF and PALF. As a result, these reinforcement fibres in the biocomposites would hasten the degradation process. In addition, CF and PALF can be easily reduced into simple biomass, causing minimal harm to the environment [50].

The biodegradability level of biocomposites was assessed by evaluating the weight loss (\%) of material samples after 30, 60, 90, 120, and 150 days of soil burial. Figure $5 a$,b illustrates the percentage weight loss for neat PLA and for untreated and alkali-treated CF/PALF/PLA biocomposite samples. Neat PLA shows almost no weight loss, whereas the biocomposites show weight loss and gradual degradation with burial time. The percentage weight loss in all the biocomposites was linearly related with the number of days of soil burial. An approximate weight loss of $1.8 \%$ for neat PLA and weight losses of $15.2 \%$ and $18.6 \%$ for the C30 and P30 biocomposites (Figure 5a) were observed. The weight losses for successive alkali-treated CF- and PALF-reinforced PLA biocomposites were $6.9 \%$ and $8.4 \%$ (Figure $5 b$ ). Among the hybrid biocomposites, the highest weight loss was $16.8 \%$ by C3P7, while C7P3 and C1P1 had the same values overall. The weight losses for successive alkali-treated C3P7, C1P1, and C7P3 were $7.3 \%, 6.8 \%$, and $6.9 \%$, respectively. The higher weight losses of the untreated CF- and PALF-reinforced PLA biocomposites as compared to the alkali-treated CF- and PALF-reinforced PLA biocomposites may be attributed to poor fibre matrix adhesion, leading to faster degradation [53]. The alkali treatment led to reduced hydrophilicity in fibres and, hence, less moisture absorption by the biocomposites from the soil, which ultimately led to slower degradation of biocomposites with surface-modified CF and PALF [54]. The highest levels of weight loss (18.6\% and $16.8 \%$, respectively) took place concurrently in untreated CF- and PALF-reinforced PLA biocomposites after 150 days of soil burial.

(a)

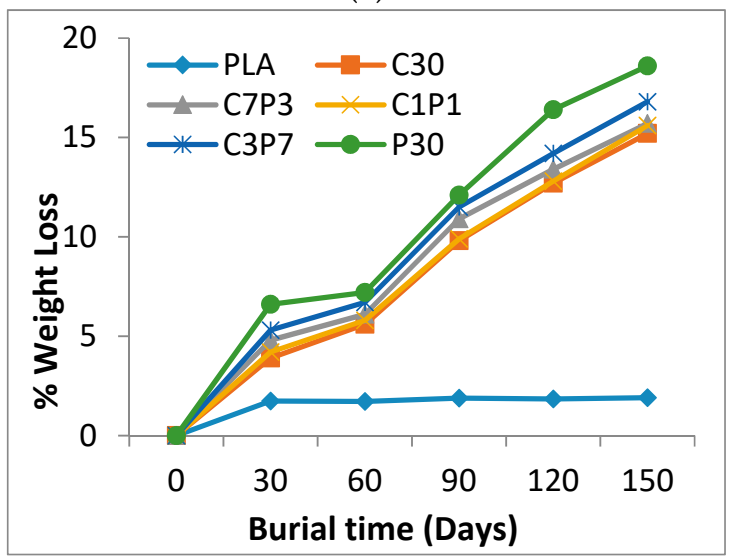

(b)

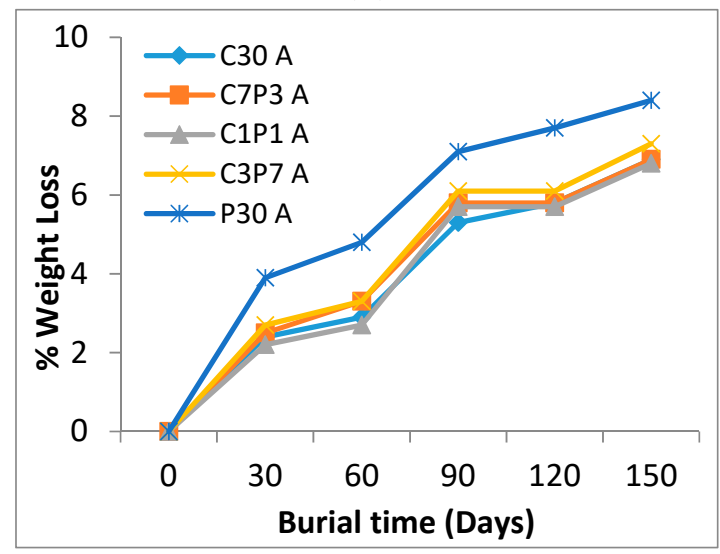

Figure 5. Weight loss (\%) of (a) PLA and untreated CF/PALF/PLA biocomposites and of (b) alkali-treated CF/PALF/PLA biocomposites.

It can be seen from Figure 6 that the neat PLA sample sheet remained almost the same, without any visible discolouration or change in its original shape. On the other hand, all the biocomposites crumbled and surfaces became rougher, forming fractures, cracks, and holes on the surface as degradation progressed owing to the degradation of fibres [55]. Nonetheless, the untreated and alkali-treated biocomposites achieved different degrees of degradation. That is, the change of shape or warping occurred more slowly in the composites with alkali-treated fibres compared to the untreated CF/PALF/PLA biocomposites, which we assumed was due to improved interfacial bonding in alkali-treated biocomposites owing to the reduced hydrophilicity in alkali-treated fibres. The results showed that biodegradation of PLA and CF/PALF/PLA biocomposites in the soil ecosystem is a 
complex process following different patterns due to uncontrolled biotic and abiotic factors. A similar trend of results was reported by Rudnik et al. [56] in their study of the degradation behaviour of PLA films and fibres by conducting soil burial in Mediterranean field conditions and laboratory simulation testing for 11 months. They concluded that the thickness and form of materials played a crucial role in the biodegradation process under soil burial and composting conditions. In general, CF/PALF/PLA biocomposite samples buried in soils degrade faster than those aged inside an accelerated weathering chamber. Morphological indications are presented in Figures 2 and 6.

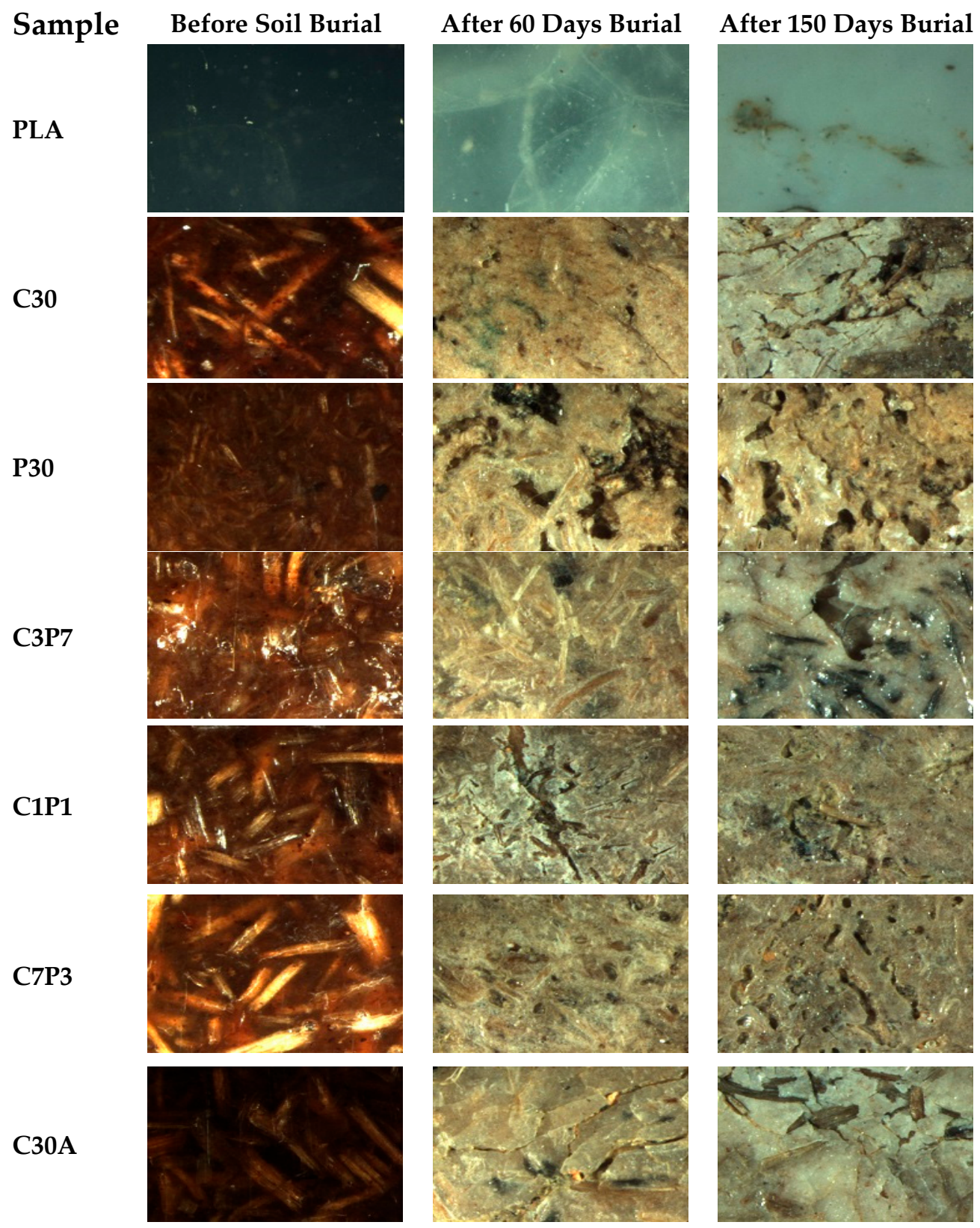

Figure 6. Cont. 
P30A
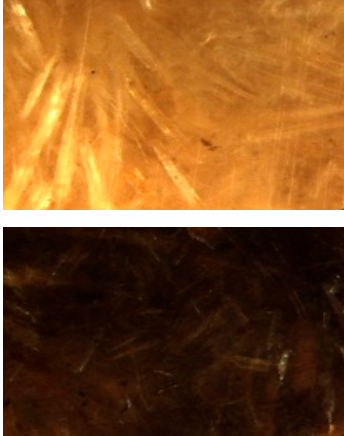

C3P7A

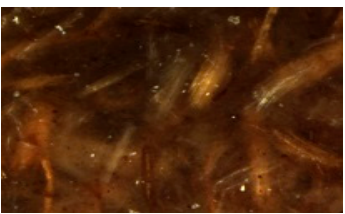

C1P1A

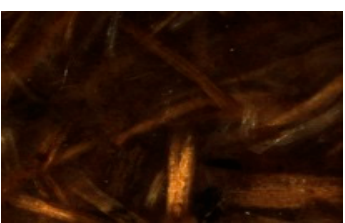

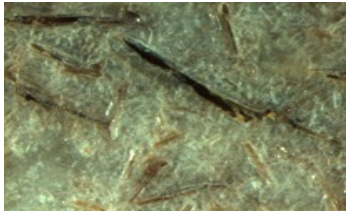
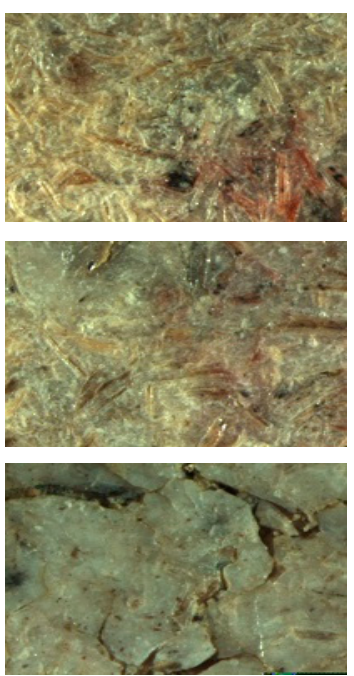
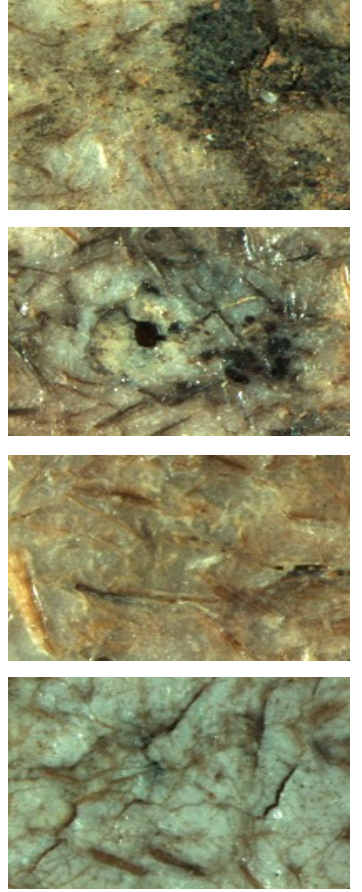

Figure 6. Image Analyser photographs of soil-degraded and unburied PLA sheets and $\mathrm{CF} / \mathrm{PALF} / \mathrm{PLA}$ biocomposites.

\section{Conclusions}

The biodegradability of a lignocellulosic composite largely depends on its polymer matrix, and the rate of biodegradation depends on many environmental factors, such as moisture, light (radiation), temperature, and microbes. Biodegradation was evaluated by soil burial and accelerated weathering tests. Changes in physical and morphological properties were observed in the biocomposites after weathering. It was found that the degradation rate of PLA was lower than that of CF/PALF/PLA biocomposites after $250 \mathrm{~h}$ of accelerated weathering. The effect of weathering on the morphology of the biocomposites was characterised by the formation of cracks and fractures, increased surface roughness, and colour and weight change as a result of degradation. Biocomposites degrade after weathering through photo-radiation, thermal degradation, oxidation, and hydrolysis. Water enhances the rate of degradation through the swelling of fibre, which leads to further light dispersion. The soil burial tests imply good biodegradability of the CF/PALF/PLA biocomposites. All the biocomposites showed weight loss and gradual degradation with burial time. The percentage weight loss in all the biocomposites was linearly related with the number of days of soil burial. C3P7 showed the highest weight loss among the hybrid biocomposites, i.e., 16.8\%, while C7P3 and C1P1 had the same values overall. The weight losses for successive alkali-treated C3P7, C1P1, and C7P3 were 7.3\%, $6.8 \%$, and $6.9 \%$, respectively. Thisdifference can be attributed to poor fibre matrix adhesion, leading to faster degradation. The alkali treatment led to reduced hydrophilicity in fibres and, hence, less moisture absorption by the biocomposites from the soil, ultimately leading to slower degradation of the biocomposites with surface-modified CF and PALF. From this study, we can conclude that untreated CF/PALF/PLA biocomposites would be a more favourable choice owing to their better biodegradability and are suitable for the suggested biodegradable food packaging applications.

Author Contributions: Conceptualization, M.J.; Funding acquisition, S.S.; Investigation, R.S.; Methodology, M.J.; Supervision, M.J.; Writing—original draft, revision \& editing, R.S.; Writing—review \& editing, Experimental supervision, M.A. All authors have read and agreed to the published version of the manuscript.

Acknowledgments: The authors extend their gratitude to Institute of Tropical Forestry and Forest Products (INTROP), Universiti Putra Malaysia for providing the research platform. This research was partly funded by King Mongkut's University of Technology North Bangkok through the Post-Doc Program KMUTNB-Post-62-03. 
Conflicts of Interest: The authors declare no conflict of interest.

\section{References}

1. Torres, F.; Rodriguez, S.; Saavedra, A. Green Composite Materials from Biopolymers Reinforced with Agroforestry Waste. J. Polym. Environ. 2019, 27, 2651-2673. [CrossRef]

2. Siakeng, R.; Jawaid, M.; Ariffin, H.; Sapuan, S.; Asim, M.; Saba, N. Natural fiber reinforced polylactic acid composites: A review. Polym. Compos. 2019, 40, 446-463. [CrossRef]

3. Asim, M.; Abdan, K.; Jawaid, M.; Nasir, M.; Dashtizadeh, Z.; Ishak, M.; Hoque, M.E. A review on pineapple leaves fibre and its composites. Int. J. Polym. Sci. 2015, 2015, 950567. [CrossRef]

4. Gheith, M.H.; Aziz, M.A.; Ghori, W.; Saba, N.; Asim, M.; Jawaid, M. Flexural, thermal and dynamic mechanical properties of date palm fibres reinforced epoxy composites. J. Mater. Res. Technol. 2019, 8, 853-860. [CrossRef]

5. Nasir, M.; Khali, D.; Jawaid, M.; Tahir, P.; Siakeng, R.; Asim, M.; Khan, T. Recent development in binderless fiber-board fabrication from agricultural residues: A review. Constr. Build. Mater. 2019, 211, 502-516. [CrossRef]

6. Madurwar, M.V.; Ralegaonkar, R.V.; Mandavgane, S.A. Application of agro-waste for sustainable construction materials: A review. Constr. Build. Mater. 2013, 38, 872-878. [CrossRef]

7. Yu, T.; Ren, J.; Li, S.; Yuan, H.; Li, Y. Effect of fiber surface-treatments on the properties of poly (lactic acid)/ramie composites. Compos. Part A Appl. Sci. Manuf. 2010, 41, 499-505. [CrossRef]

8. Song, Y.S.; Lee, J.T.; Ji, D.S.; Kim, M.W.; Lee, S.H.; Youn, J.R. Viscoelastic and thermal behavior of woven hemp fiber reinforced poly (lactic acid) composites. Compos. Part B Eng. 2012, 43, 856-860. [CrossRef]

9. Law, K.L.; Morét-Ferguson, S.E.; Goodwin, D.S.; Zettler, E.R.; DeForce, E.; Kukulka, T.; Proskurowski, G. Distribution of surface plastic debris in the eastern Pacific Ocean from an 11-year data set. Environ. Sci. Technol. 2014, 48, 4732-4738. [CrossRef]

10. Cózar, A.; Echevarría, F.; González-Gordillo, J.I.; Irigoien, X.; Úbeda, B.; Hernández-León, S.; Palma, Á.T.; Navarro, S.; García-de-Lomas, J.; Ruiz, A. Plastic debris in the open ocean. Proc. Natl. Acad. Sci. USA 2014, 111, 10239-10244. [CrossRef]

11. Gall, S.C.; Thompson, R.C. The impact of debris on marine life. Mar. Pollut. Bull. 2015, 92, 170-179. [CrossRef] [PubMed]

12. Singh, B.; Sharma, N. Mechanistic implications of plastic degradation. Polym. Degrad. Stab. 2008, 93, 561-584. [CrossRef]

13. Andrady, A.L. Plastics and Environmental Sustainability; Wiley Online Library; John Wiley \& Sons, Inc.: Hoboken, NJ, USA, 2015; pp. 145-176.

14. Islam, M.S.; Pickering, K.L.; Foreman, N.J. Influence of hygrothermal ageing on the physico-mechanical properties of alkali treated industrial hemp fibre reinforced polylactic acid composites. J. Polym. Environ. 2010, 18, 696-704. [CrossRef]

15. Barnes, D.K.; Galgani, F.; Thompson, R.C.; Barlaz, M. Accumulation and fragmentation of plastic debris in global environments. Philos. Trans. R. Soc. B 2009, 364, 1985-1998. [CrossRef] [PubMed]

16. Hopewell, J.; Dvorak, R.; Kosior, E. Plastics recycling: Challenges and opportunities. Philos. Trans. R. Soc. B 2009, 364, 2115-2126. [CrossRef]

17. Shah, A.A.; Hasan, F.; Hameed, A.; Ahmed, S. Biological degradation of plastics: A comprehensive review. Biotechnol. Adv. 2008, 26, 246-265. [CrossRef]

18. Qin, L.; Qiu, J.; Liu, M.; Ding, S.; Shao, L.; Lü, S.; Zhang, G.; Zhao, Y.; Fu, X. Mechanical and thermal properties of poly (lactic acid) composites with rice straw fiber modified by poly (butyl acrylate). Chem. Eng. J. 2011, 166, 772-778. [CrossRef]

19. Zhao, Y.; Qiu, J.; Feng, H.; Zhang, M.; Lei, L.; Wu, X. Improvement of tensile and thermal properties of poly (lactic acid) composites with admicellar-treated rice straw fiber. Chem. Eng. J. 2011, 173, 659-666. [CrossRef]

20. Siakeng, R.; Jawaid, M.; Ariffin, H.; Sapuan, S. Mechanical, dynamic, and thermomechanical properties of coir/pineapple leaf fiber reinforced polylactic acid hybrid biocomposites. Polym. Compos. 2019, 40, $2000-2011$. [CrossRef] 
21. Armentano, I.; Bitinis, N.; Fortunati, E.; Mattioli, S.; Rescignano, N.; Verdejo, R.; Lopez-Manchado, M.; Kenny, J. Multifunctional nanostructured PLA materials for packaging and tissue engineering. Prog. Polym. Sci. 2013, 38, 1720-1747. [CrossRef]

22. Wahit, M.U.; Akos, N.I.; Laftah, W.A. Influence of natural fibers on the mechanical properties and biodegradation of poly (lactic acid) and poly ( $\varepsilon$-caprolactone) composites: A review. Polym. Compos. 2012, 33, 1045-1053. [CrossRef]

23. Yussuf, A.; Massoumi, I.; Hassan, A. Comparison of polylactic acid/kenaf and polylactic acid/rise husk composites: The influence of the natural fibers on the mechanical, thermal and biodegradability properties. J. Polym. Environ. 2010, 18, 422-429. [CrossRef]

24. Fortunati, E.; Armentano, I.; Iannoni, A.; Kenny, J. Development and thermal behaviour of ternary PLA matrix composites. Polym. Degrad. Stab. 2010, 95, 2200-2206. [CrossRef]

25. Azwa, Z.; Yousif, B.; Manalo, A.; Karunasena, W. A review on the degradability of polymeric composites based on natural fibres. Mater. Des. 2013, 47, 424-442. [CrossRef]

26. Islam, M.S.; Pickering, K.L.; Foreman, N.J. Influence of accelerated ageing on the physico-mechanical properties of alkali-treated industrial hemp fibre reinforced poly (lactic acid) (PLA) composites. Polym. Degrad. Stab. 2010, 95, 59-65. [CrossRef]

27. Kumar, R.; Yakubu, M.; Anandjiwala, R. Biodegradation of flax fiber reinforced poly lactic acid. Express Polym. Lett. 2010, 4, 423-430. [CrossRef]

28. Batista, K.; Silva, D.; Coelho, L.; Pezzin, S.; Pezzin, A. Soil biodegradation of PHBV/peach palm particles biocomposites. J. Polym. Environ. 2010, 18, 346-354. [CrossRef]

29. Beninia, K.; Voorwald, H.J.C.; Cioffi, M. Mechanical properties of HIPS/sugarcane bagasse fiber composites after accelerated weathering. Procedia Eng. 2011, 10, 3246-3251. [CrossRef]

30. Dittenber, D.B.; GangaRao, H.V. Critical review of recent publications on use of natural composites in infrastructure. Compos. Part A Appl. Sci. Manuf. 2012, 43, 1419-1429. [CrossRef]

31. Ochi, S. Mechanical properties of kenaf fibers and kenaf/PLA composites. Mech. Mater. 2008, 40, 446-452. [CrossRef]

32. Chee, S.S.; Jawaid, M.; Sultan, M.; Alothman, O.Y.; Abdullah, L.C. Accelerated weathering and soil burial effects on colour, biodegradability and thermal properties of bamboo/kenaf/epoxy hybrid composites. Polym. Test. 2019, 79, 106054. [CrossRef]

33. Umar, A.; Zainudin, E.; Sapuan, S. Effect of accelerated weathering on tensile properties of kenaf reinforced high-density polyethylene composites. J. Mech. Eng. Sci. 2012, 2, 198-205. [CrossRef]

34. Dong, Y.; Ghataura, A.; Takagi, H.; Haroosh, H.J.; Nakagaito, A.N.; Lau, K.-T. Polylactic acid (PLA) biocomposites reinforced with coir fibres: Evaluation of mechanical performance and multifunctional properties. Compos. Part A Appl. Sci. Manuf. 2014, 63, 76-84. [CrossRef]

35. Van den Oever, M.; Beck, B.; Müssig, J. Agrofibre reinforced poly (lactic acid) composites: Effect of moisture on degradation and mechanical properties. Compos. Part A Appl. Sci. Manuf. 2010, 41, 1628-1635. [CrossRef]

36. Hamad, K.; Kaseem, M.; Deri, F. Rheological and mechanical characterization of poly (lactic acid)/polypropylene polymer blends. J. Polym. Res. 2011, 18, 1799-1806. [CrossRef]

37. Shih, Y.-F.; Huang, C.-C. Polylactic acid (PLA)/banana fiber (BF) biodegradable green composites. J. Polym. Res. 2011, 18, 2335-2340. [CrossRef]

38. Wang, L.; Zhang, Z.; Chen, H.; Zhang, S.; Xiong, C. Preparation and characterization of biodegradable thermoplastic Elastomers (PLCA/PLGA blends). J. Polym. Res. 2010, 17, 77-82. [CrossRef]

39. Xie, L.; Xu, H.; Wang, Z.-P.; Li, X.-J.; Chen, J.-B.; Zhang, Z.-J.; Yin, H.-M.; Zhong, G.-J.; Lei, J.; Li, Z.-M. Toward faster degradation for natural fiber reinforced poly (lactic acid) biocomposites by enhancing the hydrolysis-induced surface erosion. J. Polym. Res. 2014, 21, 357. [CrossRef]

40. Yusoff, R.B.; Takagi, H.; Nakagaito, A.N. Tensile and flexural properties of polylactic acid-based hybrid green composites reinforced by kenaf, bamboo and coir fibers. Ind. Crop. Prod. 2016, 94, 562-573. [CrossRef]

41. Siakeng, R.; Jawaid, M.; Ariffin, H.; Salit, M.S. Effects of surface treatments on tensile, thermal and fibre-matrix bond strength of coir and pineapple leaf fibres with poly lactic acid. J. Bionic Eng. 2018, 15, 1035-1046. [CrossRef]

42. Mehta, G.; Mohanty, A.K.; Drzal, L.T.; Kamdem, D.P.; Misra, M. Effect of accelerated weathering on biocomposites processed by SMC and compression molding. J. Polym. Environ. 2006, 14, 359-368. [CrossRef] 
43. Spiridon, I.; Darie, R.N.; Kangas, H. Influence of fiber modifications on PLA/fiber composites. Behavior to accelerated weathering. Compos. Part B Eng. 2016, 92, 19-27. [CrossRef]

44. Ray, B.C.; Rathore, D. Environmental damage and degradation of FRP composites: A review report. Polym. Compos. 2015, 36, 410-423. [CrossRef]

45. Campos, A.D.; Marconcini, J.; Martins-Franchetti, S.; Mattoso, L. The influence of UV-C irradiation on the properties of thermoplastic starch and polycaprolactone biocomposite with sisal bleached fibers. Polym. Degrad. Stab. 2012, 97, 1948-1955. [CrossRef]

46. Jawaid, M.; Saba, N.; Alothman, O.; Paridah, M. Effect of accelerated environmental aging on tensile properties of oil palm/jute hybrid composites. In Proceedings of AIP Conference Proceedings; AIP Publishing: Melville, NY, USA, 2016; p. 040007.

47. Schanda, J. Colorimetry: Understanding the CIE System; John Wiley \& Sons, Inc.: Hoboken, NJ, USA, 2007; pp. 25-76.

48. Ergücü, Z.; Türkün, L.; Aladag, A. Color stability of nanocomposites polished with one-step systems. Oper. Dent. 2008, 33, 413-420. [CrossRef]

49. Spiridon, I.; Leluk, K.; Resmerita, A.M.; Darie, R.N. Evaluation of PLA-lignin bioplastics properties before and after accelerated weathering. Compos. Part B Eng. 2015, 69, 342-349. [CrossRef]

50. Ohkita, T.; Lee, S.H. Thermal degradation and biodegradability of poly (lactic acid)/corn starch biocomposites. J. Appl. Polym. Sci. 2006, 100, 3009-3017. [CrossRef]

51. Harmaen, A.S.; Khalina, A.; Azowa, I.; Hassan, M.A.; Tarmian, A.; Jawaid, M. Thermal and biodegradation properties of poly (lactic acid)/fertilizer/oil palm fibers blends biocomposites. Polym. Compos. 2015, 36, 576-583. [CrossRef]

52. Kim, H.S.; Yang, H.S.; Kim, H.J. Biodegradability and mechanical properties of agro-flour-filled polybutylene succinate biocomposites. J. Appl. Polym. Sci. 2005, 97, 1513-1521. [CrossRef]

53. Rajesh, G.; Prasad, A.V.R. Tensile properties of successive alkali treated short jute iber reinforced PLA composites. Procedia Mater. Sci. 2014, 5, 2188-2196. [CrossRef]

54. Gunti, R.; Ratna Prasad, A.; Gupta, A. Mechanical and degradation properties of natural fiber-reinforced PLA composites: Jute, sisal, and elephant grass. Polym. Compos. 2018, 39, 1125-1136. [CrossRef]

55. Rashdi, A.; Sapuan, S.; Ahmad, M.; Khalina, A. Combined Effects of Water Absorption Due to Water Immersion, Soil Buried and Natural Weather on Mechanical Properties of Kenaf Fibre Unsaturated Polyester Composites (KFUPC). Int. J. Mech. Mater. Eng. 2010, 5, 11-17.

56. Rudnik, E.; Briassoulis, D. Degradaton behavior of poly (lactic acid) films and fibres in soil under Mediterranean field conditions and laboratory simulation testing. Ind. Crop. Prod. 2011, 3, 648-658. [CrossRef]

(C) 2020 by the authors. Licensee MDPI, Basel, Switzerland. This article is an open access article distributed under the terms and conditions of the Creative Commons Attribution (CC BY) license (http://creativecommons.org/licenses/by/4.0/). 